\title{
Correlação tectono-deposicional entre a margem continental brasileira e a Elevação do Rio Grande
}

\author{
Tectono-depositional correlation between the Brazilian \\ continental margin and the Rio Grande Rise
}

\author{
Adriane Gomes Pinheiro Praxedes ${ }^{1}$ (1), David Lopes de Castro ${ }^{1}$ (1) \\ ${ }^{1}$ Universidade Federal do Rio Grande do Norte - UFRN, Programa de Pós-Graduação em Geodinâmica e Geofísica, Avenida \\ Senador Salgado Filho, 3.000, Campus Universitário / Lagoa Nova, Caixa Postal 1639, CEP 59078-970, Natal, RN, BR \\ (geof.adriane@gmail.com; david@geologia.ufrn.br)
}

Recebido em 30 de janeiro de 2020; aceito em 27 de outubro de 2020

\begin{abstract}
Resumo
A margem continental brasileira foi formada pelo processo de abertura do Atlântico Sul, com a ruptura do Gondwana Oeste, e a separação entre a América do Sul e África, no Cretáceo Inferior. Por sua vez, a Elevação do Rio Grande (ERG) teria sido originada por pontos quentes ao longo da porção oceânica da placa sul-americana em movimento. Alternativamente, a ERG seria parte de crosta continental, que teria sido submersa após se desprender do continente, ou ainda seria a combinação de uma província vulcânica com um microcontinente. Nós propomos fazer uma correlação tectono-deposicional entre a ERG e a margem continental brasileira adjacente, dentro do contexto de evolução do Atlântico Sul. A partir da interpretação de seções sísmicas e dados de furos estratigráficos, foi possível identificar semelhanças entre as fácies sísmicas nos pacotes vulcanossedimentares na ERG e a margem continental brasileira mais distal, além de correlação em termos do desenvolvimento cronoestratigráfico das duas regiões. Essas semelhanças no pacote sedimentar incluem o evento vulcânico no Eoceno e a tectônica distensional no Paleógeno e no Neógeno para evidenciar evolução tectono-deposicional comum tanto na ERG quanto na margem continental adjacente.
\end{abstract}

Palavras-chave: Elevação do Rio Grande; Margem continental brasileira; Pacote sedimentar; Vulcanismo.

\begin{abstract}
The Brazilian continental margin was formed by the opening process of the South Atlantic with the rupture of the West Gondwana and the separation between South America and Africa in the Lower Cretaceous. In turn, the Rio Grande Rise (RGR) would have been originated by hot spots along the oceanic portion of the moving South American plate. Alternatively, the RGR would be part of the continental crust, which would have been submerged after detaching from the continent, or even a combination of a volcanic province with a microcontinent. We propose to make a tectono-depositional correlation between the RGR and the adjacent Brazilian continental margin, within the context of South Atlantic evolution. From the interpretation of seismic profiles and stratigraphic borehole data, it was possible to identify similarities between the seismic facies in the volcano-sedimentary sequence in the RGR and the most distal Brazilian continental margin, as well as correlation in terms of chronostratigraphic development of the two regions. These similarities in the sedimentary package include the volcanic event in the Eocene and the extensional tectonics in the Paleogen and Neogen to show a common tectono-depositional evolution in both the RGR and the adjacent continental margin.
\end{abstract}

Keywords: Rio Grande Rise; Brazilian continental margin; Sediment package; Volcanism. 


\section{INTRODUÇÃO}

O clássico processo de separação continental que ocorreu no Atlântico Sul, bem como a evolução do rifteamento associado as plumas mantélicas e a formação de microcontinentes, é objeto de investigação por meio de construções vulcânicas e do pacote sedimentar que compõem a Elevação do Rio Grande (ERG) e a margem continental brasileira (Figura 1). Assim, a correlação entre essas regiões pode fornecer importantes esclarecimentos acerca da formação e evolução do Atlântico Sul.

De acordo com O'Connor e Duncan (1990), a ERG teve origem por meio da pluma de Tristão da Cunha-Gough nas proximidades da Dorsal Mesoatlântica. E a Cadeia Walvis, do lado leste do Atlântico, teria origem comum, do ponto de vista temporal e espacial. Contudo, amostras de rochas continentais proterozoicas, coletadas pelo Serviço Geológico do Brasil (Companhia de Pesquisa de Recursos Minerais CPRM), acenderam a discussão sobre a possibilidade de crosta continental associada a pontos quentes (Santos et al., 2019).

Assim, são justificados e necessários esforços na investigação acerca da relação da margem continental brasileira com a origem e evolução da ERG. Neste trabalho, temos o objetivo de fazer uma correlação dos pacotes vulcanossedimentares e estruturas tectônicas, identificados tanto na ERG como na margem sudeste brasileira mais distal. Para isso, foram feitas interpretações de linhas sísmicas de domínio público.

Nossas interpretações sismoestratigráficas mostram que a evolução da ERG e da margem continental adjacente apresenta importantes pontos em comum, que são:

a) evento tectônico distensional no Cretáceo Superior que afetou ambas as partes;

b) evento vulcânico no Eoceno que também atingiu ambas as partes;

c) fácies sísmicas das unidades do pacote sedimentar de ambas as partes se mostram semelhantes tanto em características sísmicas quanto em idades.

\section{CONTEXTUALIZAÇÃO GEOLÓGICA DAS PARTES CORRELACIONADAS}

Na década de 1990, Souza et al. (1993) e Cainelli e Mohriak (1998) observaram semelhanças entre a margem continental brasileira e a ERG. Intrusões magmáticas alcalinas afetaram tanto a ERG quanto a região da plataforma brasileira adjacente durante o Cretáceo Superior e Terciário Inferior. Essas intrusões

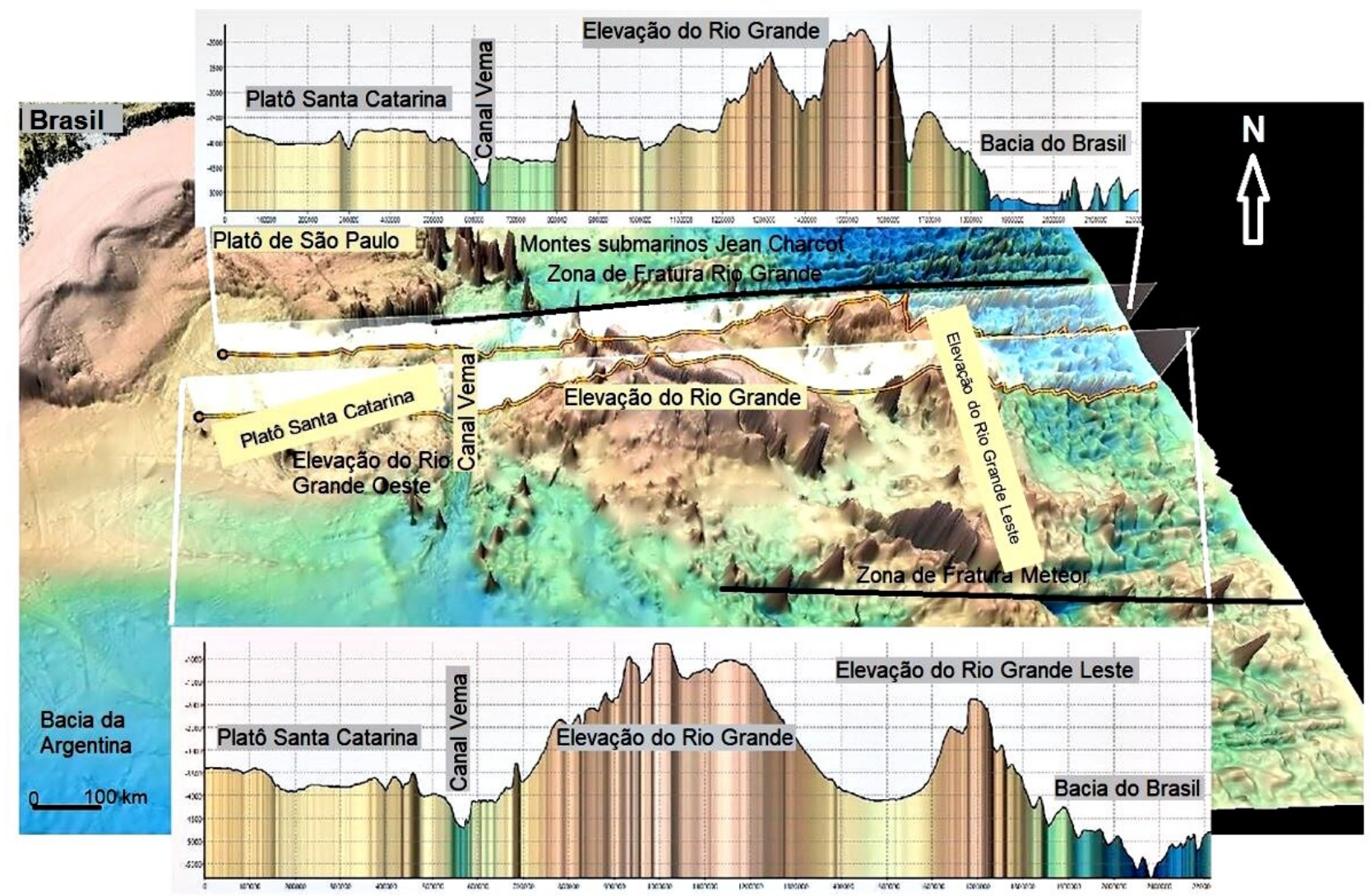

Figura 1. Mapa batimétrico do Oceano Atlântico Sul (modificado de Alberoni et al., 2019), mostrando a Elevação do Rio Grande e a margem continental adjacente. 
pós-rifte foram registradas nas bacias de Santos e Espírito Santo, tanto na crosta continental quanto na crosta oceânica, com destaque para a região de Cabo Frio e Abrolhos (Cainelli e Mohriak, 1998). Na região da ERG, esse vulcanismo foi notado nas zonas de fraturas e ao longo do Rifte Cruzeiro do Sul (Souza et al., 1993). Intrusões ígneas estão presentes ao longo da Zona de Fratura Rio Grande (Figura 1), que se estende na direção leste-oeste ao longo da borda norte da ERG até a plataforma brasileira (Severino e Gomes, 1991).

As correlações também têm importante caráter tectônico. Souza et al. (1993) sugerem que o Alto de Cabo Frio seja uma continuação terrestre das zonas de calhas do Rifte Cruzeiro do Sul, no qual também ocorre vulcanismo no Eoceno, segundo Mohriak et al. (2010). Assim, o Rifte Cruzeiro do Sul é entendido como um evento tectono-magmático relacionado a uma zona de cisalhamento que afetou tanto a litosfera continental quanto a oceânica (Souza et al., 1993; Szatmari e Mohriak, 1995). Esse evento seria provavelmente devido à reorganização das placas sul-americana $\mathrm{e}$ africana no Paleógeno e no Neógeno (Mohriak et al., 2010).

Outra estrutura interessante é a Cadeia Jean Charcot, a qual permanece sem amostragem, de modo que sua idade $\mathrm{e}$ composição são desconhecidas. A série de montes submarinos alinhados nas direções NW-SE e N-S está localizada na mesma região da ERG, onde ocorreu o evento vulcano-tectônico no Eoceno (Gambôa e Rabinowitz, 1984), o qual pode estar associado com a sua origem.

\section{Elevação do Rio Grande}

A ERG é um platô assísmico submerso, localizado a cerca de $1.500 \mathrm{~km}$ do Rio de Janeiro, separando as bacias oceânicas da Argentina e do Brasil. É limitado a norte e a sul pelas Zonas de Fraturas Rio Grande e Meteor, respectivamente (Figura 1). Esse alto teve sua divisão clássica apenas em porção oeste e porção leste feita por Gambôa e Rabinowitz (1984). Contudo, a divisão atual feita pelo NOAA(2011) considera a ERG dividida em três setores morfologicamente distintos: as duas porções definidas anteriormente e $\mathrm{o}$ acréscimo de uma porção do assoalho oceânico elevado, logo a oeste do Canal Vema (Figura 1).

A porção a oeste do Canal Vema ainda é muito pouco explorada, infere-se que corresponde a montes submarinos. A porção leste é bem mais estudada, compondo um proeminente platô com formato alongado na direção norte-sul, o que pode estar relacionado ao centro de espalhamento oceânico da Dorsal Mesoatlântica (Gambôa e Rabinowitz, 1984). A porção central é a de maior elevação, tem formato elíptico e inúmeros montes submarinos, alojados em crosta oceânica. A idade da anomalia magnética C-34 correlata a essa porção é de 83 Ma (Mohriak et al., 2010; Galvão e Castro, 2017). Rohde et al. (2013) dataram lavas basálticas toleíticas perfuradas no Furo 516F do DSDP Leg 72 (Figura 2) com idades entre 80-87 Ma. Assim, devido à posição geográfica atual da
ERG em conjunto com a provável idade de sua formação, muitos autores têm sugerido sua origem nas proximidades do centro de espalhamento oceânico da Dorsal Mesoatlântica (Gambôa e Rabinowitz, 1984; O'Connor e Duncan, 1990; Mohriak et al., 2010; Ussami et al., 2013).

Outro aspecto importante na ERG é um evento tectônico e vulcânico no Eoceno, que seria o responsável pelo soerguimento de partes da elevação acima do nível do mar. Esse evento teria formado ilhas vulcânicas que foram posteriormente erodidas (Gambôa e Rabinowitz, 1984; Mohriak et al., 2010; Praxedes et al., 2019). Essas antigas ilhas vulcânicas estão atualmente a cerca de $700 \mathrm{~m}$ abaixo do nível do mar, configurando os pontos mais altos da ERG, cujos entornos chegam a $4.000 \mathrm{~m}$ de profundidade. Amostras de basalto alcalino, coletadas em um desses montes, foram datadas em $46 \mathrm{Ma}$ (Rohde et al., 2013).

As porções central e leste da ERG (Figura 1) são cortadas pelo Rifte Cruzeiro do Sul (Figura 2). Esse extenso vale falhado tem direção NW-SE, cerca de $1.000 \mathrm{~km}$ de comprimento, $10-20 \mathrm{~km}$ de largura e profundidade de mais de $1 \mathrm{~km}$. Blocos falhados e rotacionados formam um estilo de falhamento em dominó na porção central do rifte, que é preenchido parcialmente por sequências sedimentares cenozoicas (Praxedes et al., 2019).

\section{Margem continental brasileira adjacente à Elevação do Rio Grande}

A margem continental sudeste brasileira tem contexto morfoestrutural complexo, afetada por zonas de fraturas oceânicas e altos do embasamento, como o Platô de São Paulo (Figura 1). Outro destaque na batimetria dessa área de estudo é o Canal Vema, que pode representar um centro de espalhamento oceânico abortado (Pérez-Díaz e Eagles, 2014; Fromm et al., 2017).

O limite norte da ERG é marcado pela Zona de Fratura Rio Grande (Figura 1), que se estende na margem continental adjacente. Essa é a descontinuidade da crosta mais importante nessa porção da margem. Gambôa et al. (1981) caracterizaram como um lineamento oceânico, que separa as bacias de Santos e Pelotas. A Zona de Fratura Rio Grande também limita o Platô de São Paulo a sul.

O Platô de São Paulo é um elemento fisiográfico proeminente na configuração da margem (Figura 1), com área superior a $400.000 \mathrm{~km}^{2}$, aproximadamente $1.000 \mathrm{~km}$ de comprimento e quase $300 \mathrm{~km}$ de largura em sua porção norte, atingindo o comprimento máximo de $800 \mathrm{~km}$ em sua porção sul (Alberoni et al., 2019). Nesse platô, três níveis batimétricos diferentes são observados - 1, na faixa isobatimétrica entre 2.500 e $3.500 \mathrm{~m}$, com morfologia do fundo do mar irregular associada à deformação halocinética; 2 (3.500 a 4.000 m); e $3(4.000$ a 4.500 m) -, resultantes da ação combinada de fundo retrabalho das correntes de água, bem como do avanço dos complexos turbidíticos da encosta abaixo associados a grandes canais submarinos (Alberoni et al., 2019). O platô também é formado por altos 
vulcânicos, alguns deles mais raso que $2.500 \mathrm{~m}$ de profundidade de água (Alberoni et al., 2019). O Platô de São Paulo seria uma elevação continuada da ERG que teria sido recoberta por evaporitos (Baccar, 1970; Leyden et al., 1971; Alves, 1999). A espessura do pacote sedimentar no Platô de São Paulo é de cerca de $4.000 \mathrm{~m}$, o qual teria origem na erosão decorrente do soerguimento da Serra do Mar, bem como de outras fontes de sedimentos continentais mais a sul (Santos, 2010).

De acordo com Le Pichon et al. (1971), o Canal Vema trata-se de feição erosiva, visto que o relevo do embasamento abaixo do canal mostra-se bastante irregular. Seções transversais ao longo do Canal mostram que sua porção mais profunda fica predominantemente a oeste (Le Pichon et al., 1971). Mézerais et al. (1993) o classificaram como Leque Contornítico Vema, um corpo sedimentar de considerável dimensão a norte, na porção final do Canal. O Canal Vema é uma importante conexão oceânica entre as bacias do Brasil e da Argentina (Gambôa et al., 1981; Gambôa e Rabinowitz, 1984). Nessa área, há fortes correntes de fundo devido ao fluxo de Água de Fundo da Antártica (AFA) para norte e também ao fluxo de Água Profunda do Atlântico Norte (APAN) para sul (Faugères et al., 1993).

Por fim, a Bacia Sudeste do Brasil é limitada a leste pela Dorsal Mesoatlântica, a oeste pelos platôs de São Paulo e de Santa Catarina e pelo talude continental, e a sul pela ERG (Lima, 2003). Trata-se de um conjunto de bacias oceânicas que são partes integrantes da evolução tectono-sedimentar da margem continental. Essas bacias oceânicas estão relacionadas com a ruptura do Gondwana, com origens associadas a semelhantes processos formadores de bacias (Milani et al., 2007). Inicialmente, ocorreu um estágio de deriva continental, que nas bacias marginais foi marcado pelo desenvolvimento de amplas plataformas carbonáticas. Com o avanço da separação, somado às modificações climáticas decorrentes do extenso oceano formado, houve a inibição da deposição carbonática, e as sequências sedimentares passaram a ser predominantemente siliciclásticas, o que persiste até hoje (Milani et al., 2007).

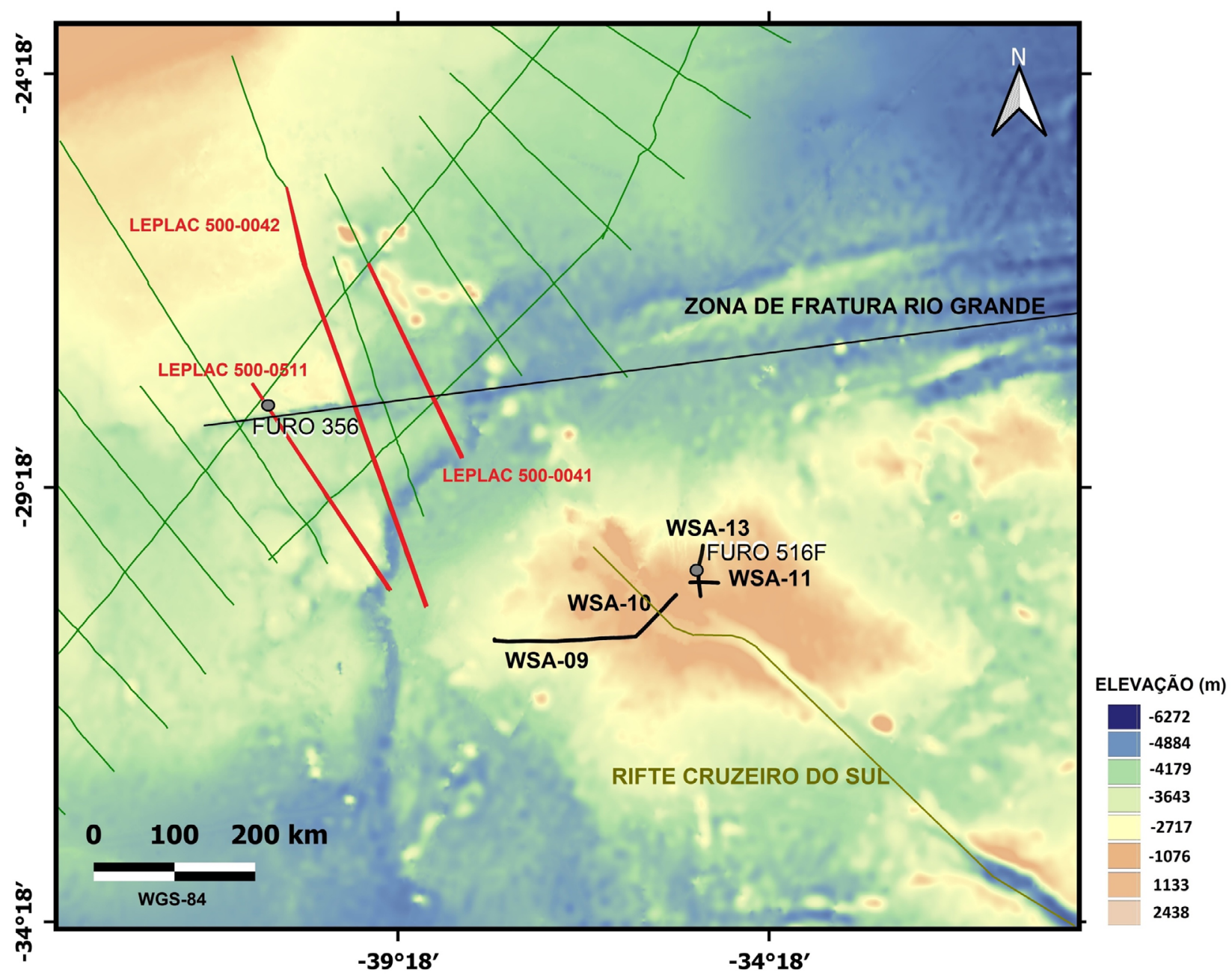

Figura 2. Mapa batimétrico do Atlântico Sul, mostrando a área de estudo com as linhas sísmicas descritas no presente estudo (dados batimétricos de Ryan et al., 2009). 


\section{MATERIAIS E MÉTODOS}

Os dados sísmicos multicanais 2D de domínio público utilizados neste trabalho são oriundos de dois projetos distintos:

- Projeto Levantamento da Plataforma Continental Brasileira (LEPLAC), cedido pela Diretoria de Hidrografia e Navegação (DHN) da Marinha do Brasil;

- Banco de dados do Instituto de Geofísica da Universidade do Texas (University of Texas Institute of Geophysics UTIG, 2015).

As seções sísmicas da UTIG sobre a ERG foram reprocessadas e interpretadas por Praxedes et al. (2019) e as linhas LEPLAC 500-0041, 500-0042 e 500-0511 (Figura 2), na margem continental adjacente, são apresentadas neste estudo e correlacionadas com as sequências sismoestratigráficas da ERG.

A interpretação das linhas sísmicas LEPLAC 500-0041, 500-0042 e 500-0511 foi realizada com base na correlação com as unidades encontradas no Furo DSDP site 356 (Figura 2). As características das fácies sísmicas dessas unidades foram correlacionadas com as linhas wsa- 09 , wsa- 10 , wsa- 11 e wsa-13 sobre a ERG, que, por sua vez, foram interpretadas com base na coluna estratigráfica do Furo DSDP site 516F (Figura 2).

Embora o Furo 516F usado na interpretação esteja a cerca de $800 \mathrm{~km}$ de distância das 3 linhas do levantamento LEPLAC, as unidades identificadas no furo mostram-se semelhantes às encontradas por outros trabalhos na mesma porção da plataforma brasileira (Mohriak et al., 2008; Capistrano, 2012), conforme mostrado na Figura 3.

Capistrano (2012) também observou em sua interpretação das mesmas linhas LEPLAC as seis unidades no pacote sedimentar acima do embasamento acústico (Tabela 1), com idades também muito parecidas com as idades das unidades encontradas no pacote sedimentar na ERG (Tabela 2).

\section{RESULTADOS}

As unidades encontradas tanto na ERG quanto na margem continental adjacente foram identificadas no Furo DSDP
$516 \mathrm{~F}$ e correlacionadas com as sequências sísmicas da linha wsa-13, que está a aproximadamente $3 \mathrm{~km}$ do furo (Figura 2).

No Furo 516F (Figura 3), as unidades mais profundas (VII e VIII) correspondem ao embasamento basáltico datado de 87-80 $\mathrm{Ma}$, equivalente ao Santoniano/Coniciano, a uma profundidade de $1.250 \mathrm{~m}$ (Rohde et al., 2013). Essas duas unidades correspondem ao embasamento acústico identificado nas linhas wsa09, wsa-10, wsa-11 e wsa-13 na ERG (Figura 2) e são correlatas ao embasamento acústico observado nas linhas LEPLAC 500-0041, 500-0042 e 500-0511 (Figuras 4 a 7). Com relação ao comportamento da morfologia do embasamento acústico na Linha 500-0041 (Figura 5), ele é elevado a noroeste devido aos Montes Submarinos Jean Charcot, em direção a sudeste, ele vai se tornando mais profundo, mas com alguns altos locais, que intrudem e deformam o pacote sedimentar até as quatro unidades superiores, tornando-se praticamente plano no Canal Vema. O embasamento acústico na Linha 500-0042 (Figura 6) é tão afetado pela tectônica de sal a noroeste, que não foi possível mapeá-lo na parte proximal do Platô de São Paulo, mas na região mais distal o embasamento acústico torna-se visível, com relevo bastante acidentado, alternando vales profundos $\mathrm{e}$ altos que chegam até a superfície oceânica na Zona de Fratura Rio Grande, para sudeste. $\mathrm{O}$ topo do embasamento apresenta relevo menos irregular até a região do Canal Vema. O embasamento acústico da Linha 500-0511 (Figura 7) forma um extenso vale central confinado entre a Zona de Fratura Rio Grande, a NO, e a porção oeste da ERG, a SE, cujo limite oeste é dado pelo Canal Vema, um espesso pacote sedimentar depositado no vale central, cujo topo irregular sugere formação carbonática com sedimentação subárea ou período posterior de soerguimento e erosão.

A unidade sobrejacente (Unidade VI) apresenta característica acústica transparente, isto é, com refletores de baixa amplitude. Essa unidade é composta de calcários de idades entre 84 e $67 \mathrm{Ma}$, que vai do Santoniano/Coniciano ao Maastrichtiano. A Unidade VI foi identificada nas linhas wsa-09, wsa-10, wsa-11 e wsa-13 na ERG e também nas linhas LEPLAC 500-0041, 500-0042 e 500-0511 (Figura 4).

A Unidade $\mathrm{V}$ acima é composta de calcário nanofóssil e foi datada entre 67-47 Ma, do Maastrichtiano ao Eoceno

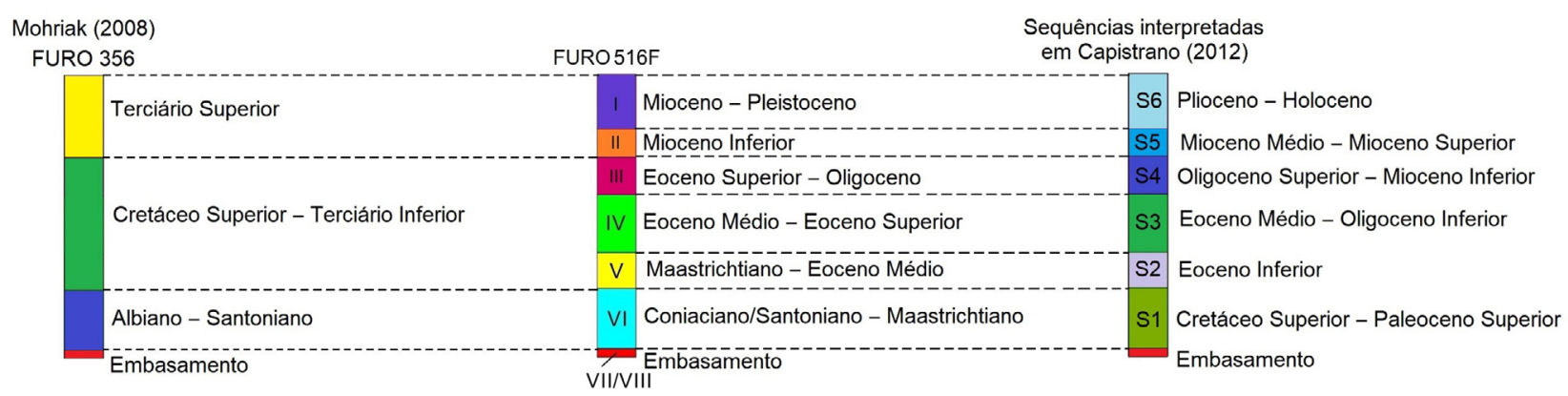

Figura 3. Correlação entre os pacotes sedimentares observados nos furos DSDP 356 (Mohriak et al., 2008) e 516F (Gambôa e Rabinowitz, 1984) e as sequências sismoestratigráficas interpretadas por Capistrano (2012) na Linha 500-0511. 
Médio (Walton et al., 1983). Os refletores dessa unidade são contínuos e de alta amplitude, cujo padrão sísmico foi identificado em todas as linhas sísmicas em estudo.

Logo acima, a Unidade IV é composta de calcário pelágico, com idades entre 47 e $40 \mathrm{Ma}$, que corresponde ao Eoceno
Médio e Eoceno Superior. Essa unidade contém turbiditos com camadas de detritos biogênicos e brechas e cinzas vulcânicas. A Unidade IV apresenta baixa refletividade (Figura 4).

A Unidade III, depositada desde o Eoceno Superior ao Oligoceno (40-23 Ma; Barker, 1983), é composta por

Tabela 1. Sequências observadas na margem continental brasileira.

\begin{tabular}{|c|c|c|c|}
\hline Sequências & Característica sísmica & Litologia & Idade \\
\hline S7 & $\begin{array}{l}\text { refletores plano-paralelos, } \\
\text { levemente ondulados } \\
\text { a transparentes }\end{array}$ & $\begin{array}{l}\text { intensificação da circulação } \\
\text { da Água Profunda do } \\
\text { Atlântico Norte e depósito de } \\
\text { deriva contornítica }\end{array}$ & Plioceno Inferior ao Recente \\
\hline S6 & $\begin{array}{l}\text { setor norte: refletores } \\
\text { ondulados; setor centro- } \\
\text { sul: fácies com clinoformas } \\
\text { sigmoidais a oblíquas }\end{array}$ & $\begin{array}{l}\text { grande atividade erosiva, } \\
\text { depósito de deriva sedimentar }\end{array}$ & $\begin{array}{l}\text { Mioceno Superior } \\
\text { ao Plioceno Inferior }\end{array}$ \\
\hline S5 & $\begin{array}{l}\text { setor norte: refletores ondulados } \\
\text { a transparentes }\end{array}$ & $\begin{array}{c}\text { sistema de circulação } \\
\text { termohalina e depósitos } \\
\text { de deriva contornítica do } \\
\text { tipo confinado }\end{array}$ & $\begin{array}{l}\text { Mioceno Inferior } \\
\text { ao Mioceno Superior }\end{array}$ \\
\hline S4 & $\begin{array}{c}\text { setor norte: refletores plano- } \\
\text { paralelos na base a ondulados } \\
\text { transparentes no topo; e o } \\
\text { setor sul e central: refletores } \\
\text { plano-paralelos }\end{array}$ & $\begin{array}{l}\text { aumento do aporte sedimentar } \\
\text { a partir do início de uma } \\
\text { regressão e depósitos de deriva } \\
\text { contornítica do tipo confinado }\end{array}$ & $\begin{array}{l}\text { Oligoceno Inferior } \\
\text { ao Mioceno Inferior }\end{array}$ \\
\hline S3 & $\begin{array}{c}\text { fácies sísmicas plano-paralelas } \\
\text { com gradação para fácies } \\
\text { onduladas e transparentes em } \\
\text { posição de talude }\end{array}$ & $\begin{array}{c}\text { entrada da Água de Fundo da } \\
\text { Antártica (AAF) com a escavação } \\
\text { de canais submarinos }\end{array}$ & $\begin{array}{l}\text { Eoceno Inferior } \\
\text { ao Oligoceno Inferior }\end{array}$ \\
\hline S2 & $\begin{array}{c}\text { refletores plano-paralelos de } \\
\text { alta amplitude e frequência } \\
\text { superiores a S1 }\end{array}$ & depósitos de deriva sedimentar & $\begin{array}{l}\text { Paleoceno Superior } \\
\text { ao Eoceno Inferior }\end{array}$ \\
\hline S1 & $\begin{array}{l}\text { refletores plano-paralelos, de } \\
\text { alta amplitude e frequência baixa }\end{array}$ & $\begin{array}{l}\text { fluxos gravitacionais } \\
\text { e hemipelágicos }\end{array}$ & $\begin{array}{l}\text { Embasamento } \\
\text { ao Paleoceno Superior }\end{array}$ \\
\hline
\end{tabular}

Fonte: modificado de Capistrano (2012).

Tabela 2. Unidades litológicas encontradas no Furo DSDP 516F.

\begin{tabular}{|c|c|c|c|}
\hline Unidades & Profundidade $(\mathrm{m})$ & Litologia & Idade \\
\hline I & $0-193$ & Foraminífero e nanofóssil ooze & Recente ao Mioceno Superior \\
\hline II & $193-332$ & $\begin{array}{l}\text { Foraminífero - nanofóssil } \\
\text { semiconsolidado ooze e giz }\end{array}$ & $\begin{array}{c}\text { Mioceno Superior } \\
\text { ao Oligoceno Inferior }\end{array}$ \\
\hline III & $332-634$ & $\begin{array}{c}\text { Nanofóssil e foraminífero - } \\
\text { nanofóssil giz }\end{array}$ & $\begin{array}{l}\text { Oligoceno Inferior } \\
\text { ao Eoceno Inferior }\end{array}$ \\
\hline IV & $634-874$ & $\begin{array}{c}\text { Nanofóssil, foraminífero giz } \\
\text { e calcários com turbiditos e } \\
\text { camadas de cinzas }\end{array}$ & Eoceno Médio \\
\hline V & 874-1.000 & Calcários microcristalinos & $\begin{array}{c}\text { Eoceno Médio } \\
\text { ao Paleoceno Superior }\end{array}$ \\
\hline VI & $1.000-1.240$ & $\begin{array}{l}\text { Calcários, calcários } \\
\text { marinhos e argilito }\end{array}$ & $\begin{array}{l}\text { Paleoceno Superior ao } \\
\text { Santoniano/Coniaciano }\end{array}$ \\
\hline VII & $1.240-1.252$ & $\begin{array}{c}\text { Calcários e brechas vulcânicas } \\
\text { sobre basalto }\end{array}$ & Coniaciano (?) \\
\hline VIII & $1.252-1.270$ & Basalto & \\
\hline
\end{tabular}

Fonte: modificado de Barker et al. (1982). 
calcários e um tipo de calcário marinho poroso constituído de micro-organismos e conchas de carbonato de cálcio. Seu padrão de reflexões sísmicas é subparalelo e de alta amplitude.
A Unidade II, do Mioceno Inferior, é composta de nanofósseis oozes e gizes de idade aproximada de $20 \mathrm{Ma}$. Apresenta refletores contínuos com amplitudes médias a altas.
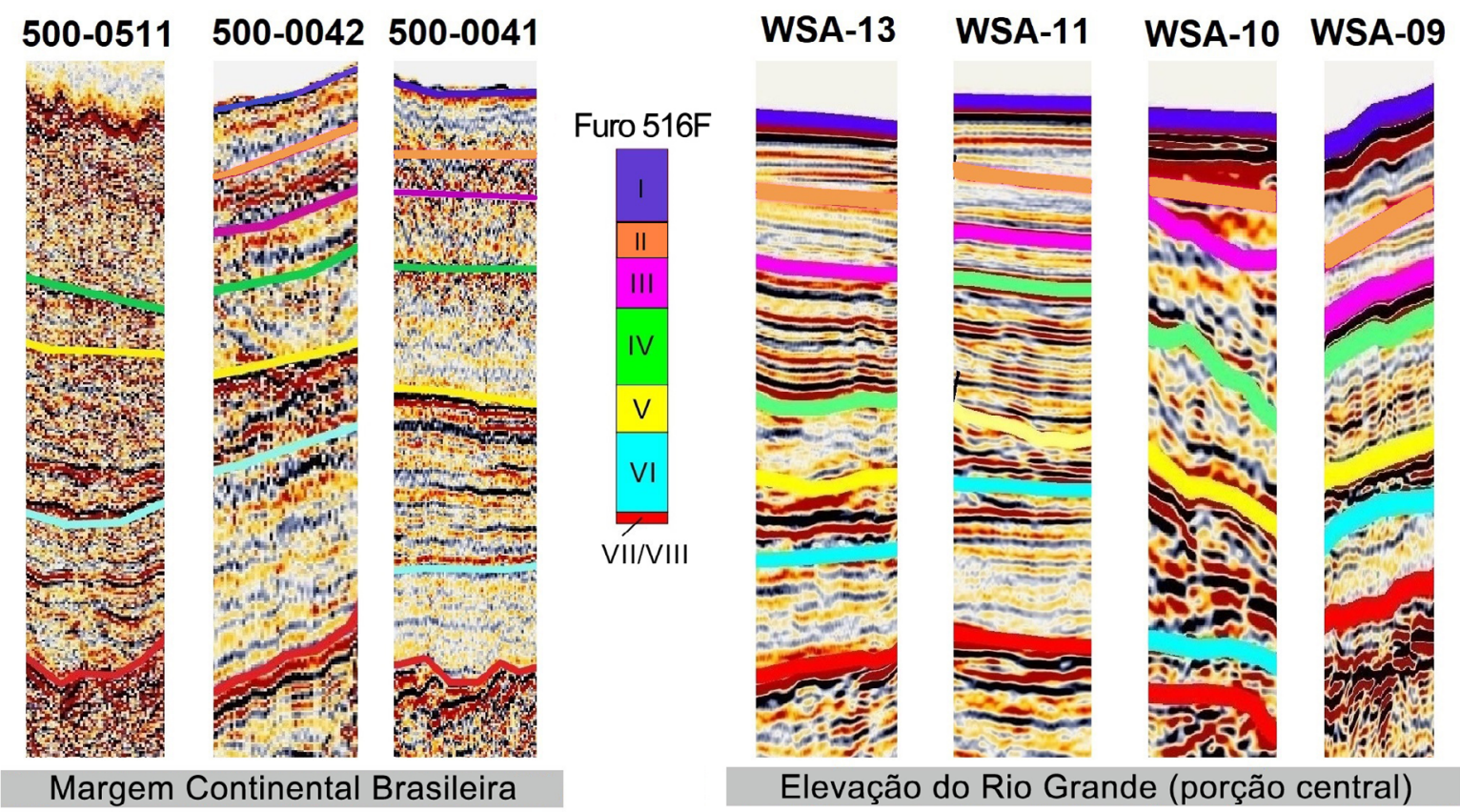

Figura 4. Semelhanças entre as fácies sísmicas das unidades estratigráficas interpretadas nas linhas sísmicas da margem continental brasileira e da porção central da Elevação do Rio Grande.

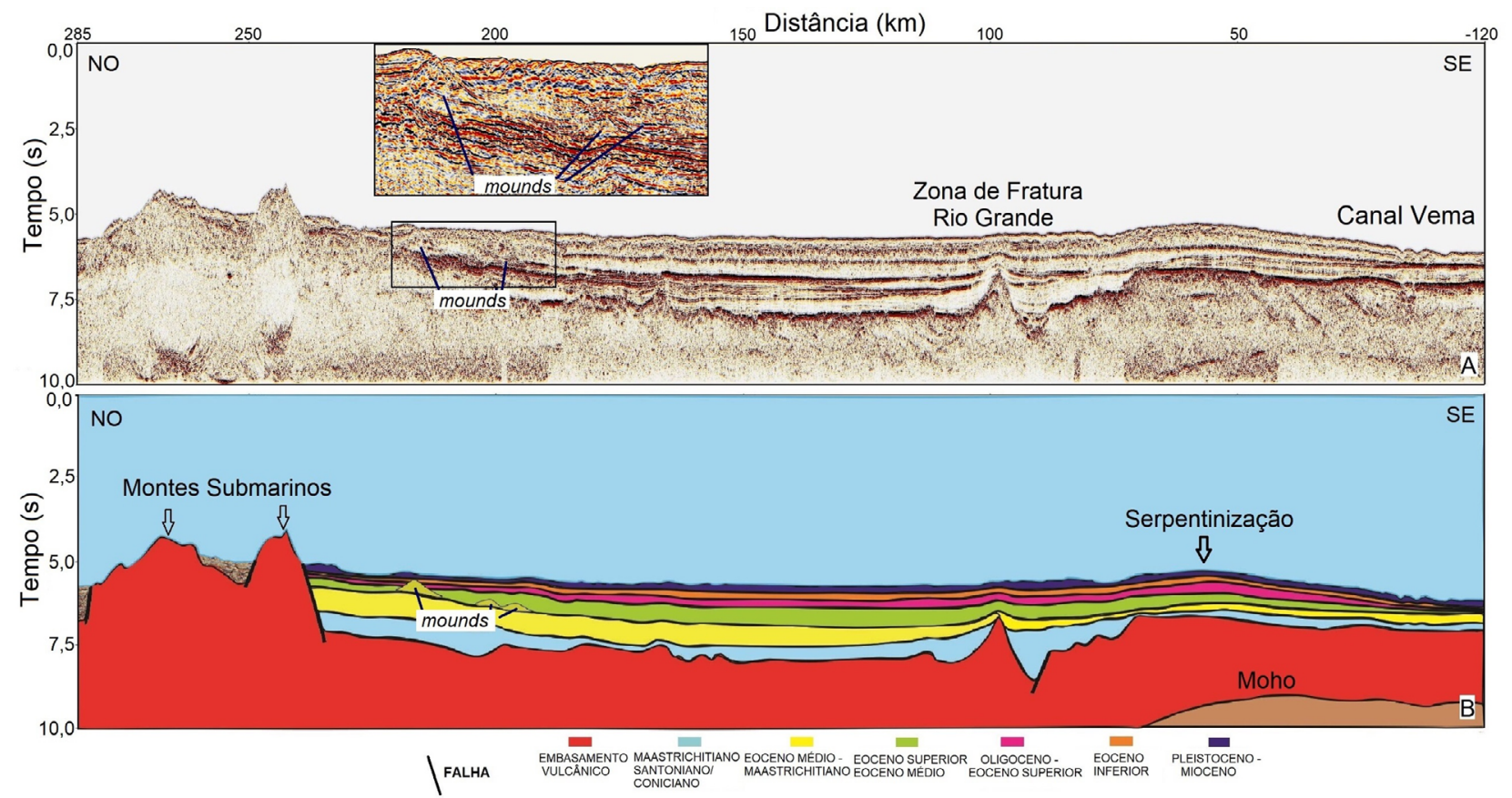

Figura 5. Linha sísmica LEPLAC 500-0041, (A) não interpretada e (B) interpretada, mostrando o embasamento acústico e as sequências sismoestratigráficas, com destaque para os Montes Submarinos Jean Chacot, a Zona de Fratura Rio Grande e o Canal Vema. 


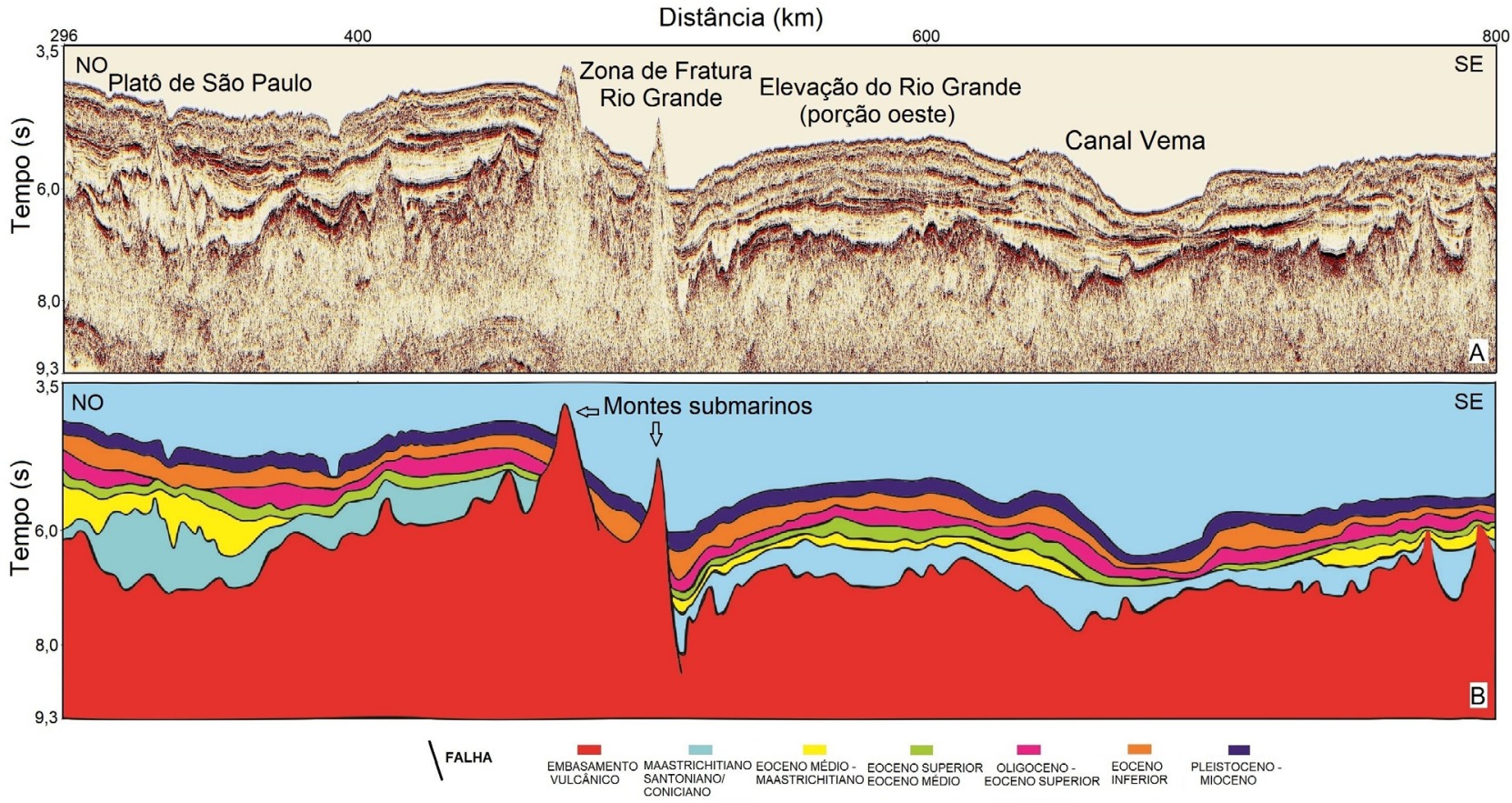

Figura 6. Linha sísmica LEPLAC 500-0042, (A) não interpretada e (B) interpretada, mostrando o embasamento acústico e as sequências sismoestratigráficas, com destaque para o Platô de São Paulo, a Zona de Fratura Rio Grande, a Elevação do Rio Grande (porção oeste) e o Canal Vema.
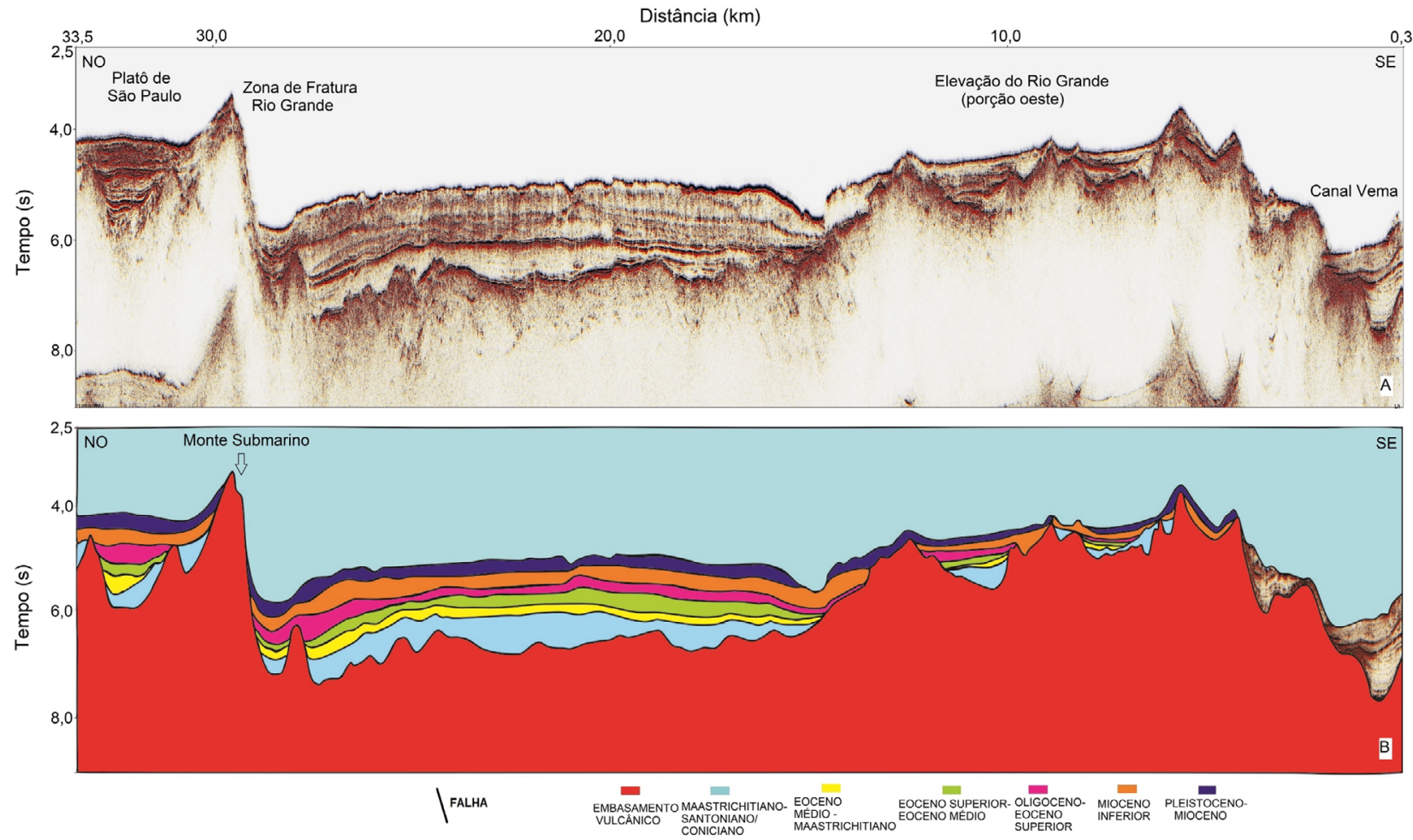

Figura 7. Linha sísmica LEPLAC 500-0511, (A) não interpretada e (B) interpretada, mostrando o embasamento acústico e o pacote sedimentar, com destaque para feições importantes que são a Zona de Fratura Rio Grande, a Elevação do Rio Grande (porção oeste) e o Canal Vema. 
Por fim, a Unidade I, que fica no topo do pacote sedimentar, é composta de calcário oólitico com idade aproximada de $20 \mathrm{Ma}$, do Mioceno ao Pleistoceno.

Os refletores nas três unidades acima do embasamento acústico são plano-paralelos e há transição para fácies sísmicas semitransparentes e caóticas nas três unidades mais superiores. Tal padrão sísmico seria devido a maior velocidade das correntes oceânicas a partir do Oligoceno (Capistrano, 2012). Outra característica comum entre as linhas sísmicas da ERG e as da margem continental brasileira é que os saltos do embasamento ao longo da área de estudo quase não alteraram as duas unidades mais superiores (Figura 5), sugerindo período de quietude tectônica no Neógeno.

Nas linhas 500-0511 e 500-0042 as unidades VI, II e I são mais espessas em relação às unidades V, IV e III. Na Linha 500-0041, as unidades VI, V e IV são mais espessas do que as unidades III, II e I.

$\mathrm{Na}$ Linha 500-0511 (Figura 7), os refletores estão muito caóticos e a qualidade do sinal sísmico não está muito boa. Porém, essa linha mostra tanto a ERG (porção oeste) quanto a margem continental adjacente e em ambas as partes podemos observar ascensões do embasamento, que chega a alcançar o fundo oceânico. Essa semelhança entre a margem continental brasileira $\mathrm{e} \mathrm{a} \mathrm{ERG}$, em relação à presença de montes submarinos ao longo do pacote sedimentar, é mostrada na Figura 8, a qual mostra a ocorrência desses montes tanto na ERG quanto na margem continental adjacente. Esse vulcanismo possivelmente teria afetado ambas as regiões no Eoceno.

Da mesma forma que na Linha 500-051, a Linha 5000042 mostra as duas partes correlatas (Figura 6). Neste caso, podemos destacar as semelhanças no pacote sedimentar, com a identificação de unidades correlatas depositadas.

$\mathrm{Na}$ Linha 500-0041, a Unidade VI se torna mais espessa em direção à Zona de Fratura Rio Grande (Figura 5). Nessa região, essa unidade é intrudida por um corpo magmático eocênico/ miocênico (pois afeta a Unidade II do Mioceno Inferior) e a Unidade $\mathrm{V}$ apresenta terminações onlaps, possivelmente associadas ao soerguimento da ERG, a oeste. Evidências desse soerguimento são downlaps da Unidade IV sobre a V no Canal Vema. A ascensão tardia de todo o pacote sedimentar próximo ao Canal Vema pode ser um processo mais recente de serpentinização da crosta oceânica, com aumento de volume (Figura 5).

Na Linha 500-0041 também observamos mounds dentro do pacote sedimentar (Figura 5). Essas estruturas montiformas foram também observadas dentro do pacote sedimentar na ERG, conforme mostrado na Figura 9. Essas estruturas possivelmente estão associadas a chaminé de gás ou atividade hidrotermal (Praxedes et al., 2019), ou ainda ao vulcanismo do Eoceno (Gambôa e Rabinowitz, 1984). Os mounds ocorrem nas proximidades de expressivos montes submarinos. No caso da ERG, os montes submarinos são observados nas linhas sísmicas wsa-09 e wsa-10. Esses altos aflorantes controlam e modificam a deposição de sedimentos (Capistrano, 2012).

O Canal Vema pode ser visto nas seções sísmicas das Figuras 5 a 7, de modo bastante suave a norte (Linha 5000041), e vai ficando cada vez mais íngreme e falhado para sul (linhas 500-0042 e 500-511) e com o pacote sedimentar cada vez mais fino. Já a Zona de Fratura Rio Grande foi interpretada nas linhas 500-0511, 500-0042 e 500-0041 como expressiva falha de alto ângulo e pronunciado rejeito vertical. Em todas essas linhas sísmicas se observam altos significativos do embasamento aflorando no fundo oceânico, que seriam montes submarinos, possivelmente associados ao vulcanismo no Eoceno.

\section{DISCUSSÃO}

Podemos destacar que tanto a ERG quanto a sua margem continental adjacente se originaram no contexto de ruptura do Gondwana e consequente abertura oceânica. Também que

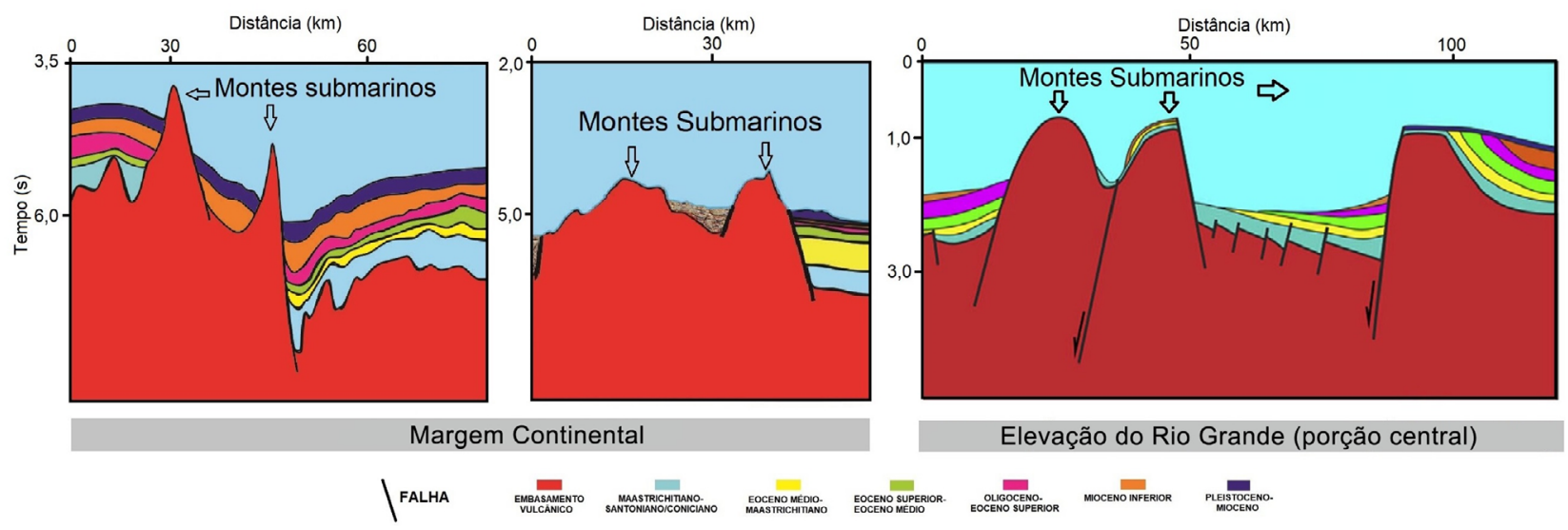

Figura 8. Semelhanças tectono-deposicionais entre a margem continental brasileira e a Elevação do Rio Grande em relação a presença de montes submarinos ao longo do pacote sedimentar, os quais estão associados ao vulcanismo no Eoceno que teria afetado ambas as regiões. 
as duas partes foram atingidas por evento magmático no Eoceno. E ainda que o evento tectônico distensional que ocorreu no Cretáceo Superior também atingiu as duas partes.

Contudo, não apenas pontos em comum podem ser destacados, algumas diferenças também são interessantes, tais como a não existência de halocinese na ERG, o que pode ser em decorrência de a ERG ainda não ter sido formada quando havia as condições favoráveis para a formação das camadas de sal na margem continental adjacente, que é mais antiga do que a ERG.

A sequência de eventos tectono-deposicionais revelada pelas linhas sísmicas interpretadas na ERG e na margem continental adjacente é descrita a seguir:

- Deposição da Sequência 1 (Unidade VI — topo azul), que é acusticamente transparente, ou seja, com refletores de baixa amplitude, de idade Santoniano/Coniciano ao Maastrichtiano. Adeposição dessa sequência foi identificada nas linhas wsa09, wsa-10, wsa-11 e wsa-13 na ERG e também nas linhas LEPLAC 500-0041, 500-0042 e 500-0511 (Figuras 5 a 7);

- Soerguimento da porção leste na margem continental, o efeito desse soerguimento pode ser mais bem observado na Linha LEPLAC 500-0511 (Figura 7);

- Deposição da Sequência 2 (Unidade V - topo amarelo) com onlaps sobre a Sequência 1, a Unidade V de idade Maastrichtiano ao Eoceno apresenta refletores contínuos e de alta amplitude (Figuras 5 a 7);

- Compactação das sequências 1 e 2 e deposição da Sequência 3 (Unidade IV - topo verde), a Unidade IV de idade entre o Eoceno Médio e Eoceno Superior apresenta baixa refletividade e foi identificada nas linhas wsa-09, wsa-10, wsa-11 e wsa-13 na ERG, bem como nas linhas LEPLAC 500-0041, 500-0042 e 500-0511 (Figuras 5 a 7);
- Corpo intrusivo nas sequências 1 e 2 e associado à Zona de Fratura Rio Grande, isso pode ser observado nas linhas LEPLAC 500-0041, 500-0042 e 500-0511 (Figuras 5 a 7);

- Basculamento a leste, que pode ser mais bem observado na Linha LEPLAC 500-0511 (Figura 7), e deposição da Sequência 4 (Unidade III - topo rosa) entre o Eoceno Superior e o Oligoceno, com padrão de reflexões subparalelo e de alta amplitude;

- Quietude tectônica com deposição da Sequência 5 (Unidade II — topo roxo), a Unidade II, de idade Mioceno Inferior, apresenta refletores contínuos com amplitudes médias a altas;

- Soerguimento a leste devido à serpentinização da crosta oceânica, isso pode ser mais bem observado na Linha LEPLAC 500-0041 (Figura 5).

\section{CONCLUSÃO}

Interpretações sismoestratigráficas mostram correlações entre o embasamento acústico e as fácies sísmicas das unidades que compõem os pacotes sedimentares nas porções central e oeste da ERG e na margem continental adjacente.

Ambas as partes foram formadas no contexto de abertura do Oceano Atlântico Sul. A ERG teria sido formada após a margem continental brasileira, contudo, em seus históricos evolutivos, podemos destacar os efeitos da tectônica distensional do Cretáceo Superior, que teria sido em decorrência de rearranjo de placas. Outro destaque são os efeitos do evento vulcânico intrusivo e extrusivo no Eoceno que atingiram ambas as partes.

Com relação às características das fácies sísmicas do pacote sedimentar na ERG e na margem continental, observamos

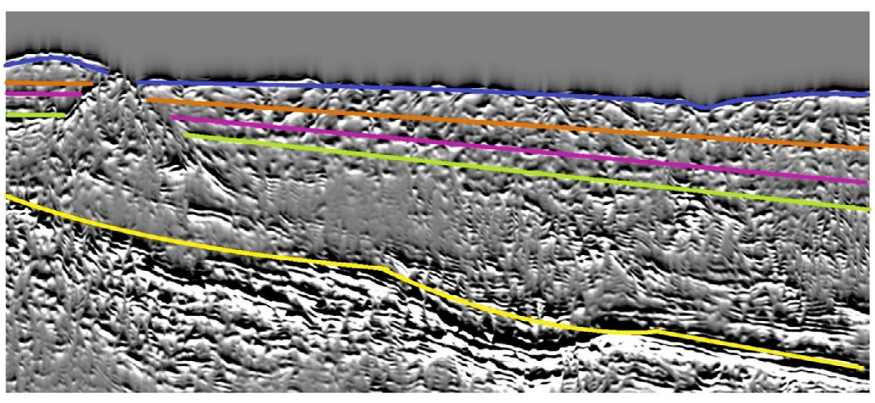

Margem Continental
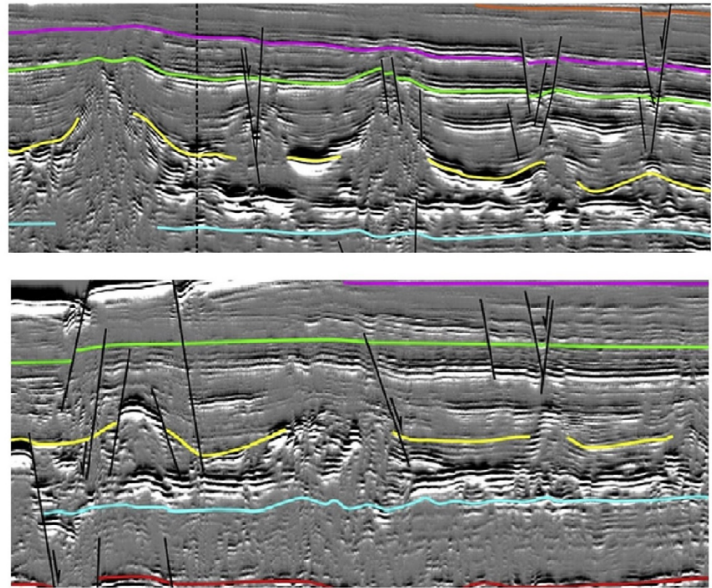

Elevação do Rio Grande (porção central)

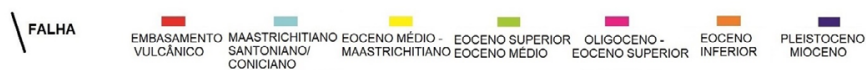

Figura 9. Mounds encontrados dentro do pacote sedimentar tanto na Elevação do Rio Grande quanto na margem continental adjacente. 
significativas semelhanças que podem ser comprovadas por meio das idades das unidades do Furo DSDP 516F (ERG) com as unidades estratigráficas observadas na margem continental brasileira mais distal. $\mathrm{O}$ apontamento da correlação entre a ERG e a porção territorial brasileira sugere que essas partes tenham histórico evolutivo comum, sendo indissolúveis.

\section{AGRADECIMENTOS}

Este estudo é parte do projeto IODP/CAPES, $n^{\circ} 13 / 2014$, coordenado pelo Dr. Peter Christian Hackspacher (Universidade Estadual Paulista "Júlio de Mesquita Filho" — UNESP). Nós agradecemos a Diretoria de Hidrografia e Navegação (DHN) da Marinha do Brasil, pelo fornecimento de dados sísmicos do projeto Levantamento da Plataforma Continental Brasileira (LEPLAC), bem como a University of Texas - Institute of Geophysics (UTIG), em Austin, e ao Deep Sea Drilling Project (DSDP), pelo fornecimento de dados sísmico e do Furo DSDP $516 \mathrm{~F}$, respectivamente. AGPP e DLC agradecem à Coordenação de Aperfeiçoamento de Pessoal de Nível Superior (CAPES) e ao Conselho Nacional de Desenvolvimento Científico e Tecnológico $(\mathrm{CNPq})$, pelas suas bolsas de doutorado e produtividade em pesquisa, respectivamente.

\section{REFERÊNCIAS}

Alberoni, A. A. L., Jeck, I. K., Silva, C. G., Torres, L. C. (2019). The new Digital Terrain Model (DTM) of the Brazilian Continental Margin: detailed morphology and revised undersea feature names. Geo-Marine Letters. https:// doi.org/10.1007/s00367-019-00606-x

Alves, R. A. (1999). Estudo sismoestratigráfico da Bacia do Brasil. Dissertação (Mestrado). Niterói: Universidade Federal Fluminense.

Baccar, M. A. (1970). Evidências geofísicas do pacote sedimentar no Plateau de São Paulo. XXIV Congresso Brasileiro de Geologia, p. 201-210. Brasília: SBG.

Barker, P. F. (1982). Site 516: Rio Grande Rise. In: P. F. Barker, R. L. Carlson et al. (eds.), Initial Reports of the Deep Sea Drilling Project, v. 72, p. 155-338. Washington, D.C.: US Government Printing Office. http://doi.org/10.2973/ dsdp.proc.72.105.1983

Barker, P. F. (1983). Tectonic evolution and subsidence history of the Rio Grande Rise. In: P. F. Barker, R. L. Carlson et al. (eds.), Initial Reports of the Deep Sea Drilling Project, v. 72, p. 953-976. Washington, D.C.: US Government Printing Office. https://doi.org/10.2973/dsdp.proc.72.151.1983
Cainelli, C., Mohriak, W. U. (1998). Geology of Atlantic Eastern Brazilian basins. In: AAPG International Conference \& Exhibition Short Course - Brazilian Geology Part II. Rio de Janeiro.

Capistrano, G. (2012). Depósitos de deriva dos Canais Vema e São Paulo. Dissertação (Mestrado). Niterói: Universidade Federal Fluminense.

Faugères, J. C., Mézerais, M. L., Stow, D. A. V. (1993). Contourite drift types and their distribution in the North and South Atlantic Oceans Basins. Sedimentary Geology, 82(14), 189-203. https://doi.org/10.1016/0037-0738(93)90121-K

Fromm, T., Jokat, W., Behrmann, J. H. (2017). Interaction between a hotspot and a fracture zone: the crustal structure of Walvis Ridge at $6^{\circ}$ E. Tectonophysics, 716, 108-120. https://doi.org/10.1016/j.tecto.2017.03.001

Galvão, I. L. G., Castro, D. L. (2017). Contribution of global potential field data to the tectonic reconstruction of the Rio Grande Rise in the South Atlantic. Marine and Petroleum Geology, 86, 932-949. https://doi.org/10.1016/j.marpetgeo.2017.06.048

Gambôa, L. A. P., Rabinowitz, P. D. (1981). The Rio Grande Fracture Zone in the Western South Atlantic and its tectonic implications. Earth and Planetary Science Letters, 52(2), 410-418. https://doi.org/10.1016/0012-821X(81)90193-X

Gambôa, L.A. P., Rabinowitz, P. D. (1984). The evolution of the Rio Grande Rise in the southwest Atlantic Ocean. Marine Geology, 58(1-2),35-58. https://doi.org/10.1016/0025-3227(84)90115-4

Le Pichon, X., Ewing, M., Truchan, M. (1971). Sediment transport and distribution in the Argentine Basin. In: L. H. Ahren, F. Press, S. N. Runcorn, H. C. Urey (eds.), Physics and Chemistry of the Earth (v. 8, p. 31-48). Nova York: Pergamon Press.

Leyden, R., Ludwig, W. J., Ewing, M. (1971). Structure of continental margin off Punta del Este, Uruguay and Rio de Janeiro, Brazil. AAPG Bulletin, 55(12), 2161-2173. https:// doi.org/10.1306/819A3E2A-16C5-11D7-8645000102C1865D

Lima, A. F. (2003). Comparação dos sistemas sedimentares profundos da Bacia Sudeste-Sul do Brasil com ênfase no Sistema Misto Columbia. Tese (Doutorado). São Paulo: Instituto Oceanográfico, Universidade de São Paulo - USP.

Mézerais, M. L., Faugères, J. C., Figueiredo, A. G., Massé, L. (1993). Contour Current Accumulation off the Vema Channel Mouth, Southern Brazil Basin: Pattern of a "Conturite Fan”. Sedimentary Geology, 82(1-4), 173-187. https://doi. org/10.1016/0037-0738(93)90120-T 
Milani, E. J., Rangel, H. D., Bueno, G. V., Stica, J. M., Winter, W. R., Caixeta, J. M., Pessoa Neto, O. C. (2007). Bacias Sedimentares Brasileiras - Cartas Estratigráficas. Boletim de Geociências da Petrobras, 15(2), 183-205.

Mohriak, W. U., Nemcok, M., Enciso, G. (2008). South Atlantic divergente margin evolution: rift-border uplift and salt tectonics in the basins of SE Brazil. In: R. J. Pankhurst, R. A. J. Trouw, B. B. Brito Neves, M. J. de Wit (eds.), West Gondwana pre-Cenozoic correlations across the South Atlantic region, v. 294, p. 365-398. Londres: Geological Society, Special Publications.

Mohriak, W. U., Nóbrega, M., Odegard, M. E., Gomes, B. S., Dickson, W. G. (2010). Geological and geophysical interpretation of the Rio Grande Rise, south-eastern Brazilian margin: extensional tectonics and rifting of continental and oceanic crusts. Petroleum Geoscience, 16(3), 231-245. https://doi.org/10.1144/1354-079309-910

National Oceanic and Atmospheric Administration (NOAA). (2011). GEBCO - Undersea Feature Names Gazetteer. Disponível em: <https://www.ngdc.noaa.gov/gazetteer/>. Acesso em: 13 abr. 2018.

O'Connor, J. M., Duncan, R. A. (1990). Evolution of the Walvis Ridge-Rio Grande Rise Hot Spot System: Implications for African and South American Plate motions over plumes. Journal of Geophysical Research, 95(B11), 17475-17502. https://doi.org/10.1029/JB095iB11p17475

Pérez-Díaz, L., Eagles, G. L. (2014). Constraining South Atlantic growth with seafloor spreading data. Tectonics, 33(9), 1848-1873. https://doi.org/10.1002/2014TC003644

Praxedes, A. G. P., Castro, D. L., Torres, L. C., Gambôa, L. A. P., Hackspacher, P. C. (2019). New insights of the tectonic and sedimentary evolution of the Rio Grande Rise, South Atlantic Ocean. Marine and Petroleum Geology, 110, 335-346. https://doi.org/10.1016/j. marpetgeo.2019.07.035

Rohde, J. K., van den Bogaard, P., Hoernle, K., Hauff, F., Werner, R. (2013). Evidence for an age progression along the Tristan-Gough volcanic track from new 40Ar/39 Ar ages on phenocryst phases. Tectonophysics, 604, 60-71. https:// doi.org/10.1016/j.tecto.2012.08.026
Ryan, W. B. F., Carbotte, S. M., Coplan, J. O., O'Hara, S. O., Melkonian, A., Arko, R., Weissel, R. A., Ferrini, V., Goodwillie, A., Nitsche, F., Bonczkowski, J.,Zemsky, R. (2009). Global multiResolution topography synthesis. Geochemistry, Geophysics, Geosystems, 10(3), Q03014.https://doi.org/10.1029/2008GC002332

Santos, R. A. (2010). Análise Sísmica de Correntes Submarinas Profundas no Terciário da Margem Continental Sul-Sudeste da América do Sul. Tese (Doutorado). Niterói: Universidade Federal Fluminense.

Santos, R. V., Ganade, C. E., Lacasse, C.M., Costa, I. S. L., Pessanha, I., Frazão, E. P., Dantas, E. L., Cavalcante, J. A. (2019). Dating Gondwanan continental crust at the Rio Grande Rise, South Atlantic. Terra Nova, 31(5), 424-429. https://doi.org/10.1111/ter.12405

Severino, M. C. G., Gomes, B. S. (1991). Projeto Leplac: Interpretação preliminar dos dados sísmicos e gravimétricos do Prospecto LEPLAC I. II Congresso Internacional da Sociedade Brasileira de Geofisica, p. 597-602. Salvador: SBGf.

Souza, K. G., Fontana, R. L., Mascle, J., Macedo, J. M., Mohriak, W. U., Hinz, K. (1993). The southern Brazilian margin: an example of a South Atlantic volcanic margin. Third International Congress of the Brazilian Geophysical Society, 2, p. 1336-1341. Rio de Janeiro: SBG.

Szatmari, P., Mohriak, W. U. (1995). Plate model of post breakup tectono magmatic activity in SE Brazil and the adjacent Atlantic. V Simpósio Nacional de Estudos TectônicosSNET 95, 213-214. Gramado.

University of Texas at Austin / Institute for Geophysics (UTIG). (2015). Disponível em: <https://ig.utexas.edu/ academic-seismic-portal-at-utig/> Acesso em: 15 out. 2015.

Ussami, N., Chaves, C. A. M., Marques, L. S., Ernesto, M. (2013). Origin of the Rio Grande Rise-Walvis Ridge reviewed integrating palaeogeographic reconstruction, isotope geochemistry and flexural modelling. Geological Society of London, 369(1), 129-146. https://doi.org/10.1144/sp369.10

Walton, W. H., Main, C. T., Sangrey, D. A., Miller, S. A. (1983). Geotechnical engineering characterization of hydraulically pistoncored deep ocean sediments. In: P. F. Barker, R. L. Carlson, et al. (eds.), Initial Reports of the Deep Sea Drilling Project, v. 72, p. 537-549. Washington, D.C.: US Government Printing Office. 